\title{
Principles of reforming an agile-compliant performance appraisal
}

Mawarny Md. Rejab, Mazni Omar, Mazida Ahmad, Syahida Hassan

School of Computing, Universiti Utara Malaysia, College of Arts and Sciences, UUM Sintok, Malaysia

\begin{tabular}{l} 
Article Info \\
\hline Article history: \\
Received Dec 20, 2018 \\
Revised Mar 17, 2019 \\
Accepted Apr 11, 2019 \\
\hline
\end{tabular}

\section{Keywords:}

Agile software development

Agile-compliant

Performance appraisal

Principles

\begin{abstract}
This paper presents principles of reforming an Agile-compliant performance appraisal. In this study, several semi-structured interviews have been carried out and discovered eight principles for reforming an Agile-compliant performance appraisal for Agile teams. Performance appraisal for software engineers in an Agile software development environment is complex and different from the traditional software development. Performance appraisal should be aligned to Agile values, principles, and practices, which advocate interactions, collaborations, teamwork, and knowledge transfer among Agile team members. Therefore, a transition to Agile Software Development requires the implementation of Agile-compliant performance appraisal. These principles embark the proper practices and guidance to support management and Agile teams in deriving and implementing an Agilecompliant performance appraisal. Therefore, the emerged principles can be a baseline in generating an Agile-compliant performance appraisal to assess Agile team members in a fair and consistent manner. This indirectly increases motivation amongst team members and tends to produce capable workforce to perform at a higher level.
\end{abstract}

Copyright $\odot 2019$ Institute of Advanced Engineering and Science. All rights reserved.

\section{Corresponding Author:}

Mawarny Md. Rejab,

School of Computing,

Universiti Utara Malaysia,

06010 Sintok, Kedah, Malaysia.

Email: mawarny@uum.edu.my

\section{INTRODUCTION}

Performance appraisal refers to a systematic process of employees' progress assessment against certain expectations including organizational objectives $[1,2]$. Performance appraisal involves a formal interaction between an employee and the supervisor or the management in identifying the strength and weakness of the employees. It focuses on assessing progress and performance of employees in order to determine the future development of employees' potential. Therefore, performance appraisal is employed to manage and align all of an organization's resources in order to achieve highest possible performance professional and career development, recognition and compensation, and salary increment and promotion exercise [3, 4]. A good performance appraisal enables team members to clearly understand a key performance indicators (KPIs) that need to be achieved [5]. Based on the KPIs, team members are able to identify their strengths and capabilities, as well as opportunities for improvement and development of required skills. Some Agile Software Development organizations still apply traditional performance appraisal solely based on individual assessment [6]. According to Alnaji and Salameh [7] and Coyle et al. [6], it is vital to have an Agile-compliant performance appraisal as Agile Software Development is team-oriented. An Agile-compliant performance appraisal should be aligned to Agile values, principles, and practices, which advocate interactions, collaborations, teamwork, and knowledge transfer. 
There is a paucity of empirical studies that focus on Agile-compliant performance appraisal [6-10]. Most studies proposed metrics, measurements, and how to assess the job performance of Agile team members. Even though literature indicates several improvements towards Agile-compliant performance appraisal, we strongly believe that there are more elements of performance appraisal including assessment criteria, assessment methods, and principles need to be dug out intensively. Dube [11] suggested the necessity to revise and reform the organization's performance appraisal system. The process of reforming performance appraisal system, however, is not easy, which tends to put pressure on management for investing and developing a new performance appraisal system [12]. Management needs to derive a proper plan for reforming performance appraisal by considering suggestions for improving the current performance appraisal. This paper aims to discuss principles for reforming an Agile-compliant performance appraisal that have been discovered through this study. Throughout semi-structured interviews with five Agile practitioners based in Malaysia, we discovered eight principles that tends to be a guideline for management and Agile teams in reforming an Agile-compliant performance appraisal.In order to present the findings of this study, this paper is structured as follows: the next section describes research method; the third section presents the findings of this study; the fourth section discusses the findings; and the last section puts forward conclusions.

\section{RESEARCH METHOD}

The principles of reforming an Agile-compliant performance appraisal are discovered through the following phases:

\subsection{Theoretical Study}

In order to understand and explore this study, we have reviewed scholarly articles related to an Agile-compliant performance appraisal in depth. The articles are selected amongst peer-reviewed articles to ensure their credibility. Then, we did critical analyses of the principles, assessment criteria and methods used in an Agile-compliant performance appraisal.

\subsection{Data Collection}

This study employed semi structured interviews as the main data collection. Five Agile practitioners have been interviewed to clearly understand how the performance of Agile team membershave been assessed and confirm the performance appraisal are aligned with Agile values, practices, and principles.

\subsection{Data Analysis}

The interviews data were analysed through content analysis involving descriptive (what is the data?) and interpretive (what was meant by the data?). The content analysis enables us to categorize the interviews data for the purpose of classification and summarization of findings. At this stage, we have discovered several principles that led to the construction of Agile-compliant performance appraisal model.

\subsection{Validation of Findings}

The outcome from this study was validated through expert reviews. Three Agile practitioners have been selected to validate theoretically and practically the emerged principles. Their feedbacks were used to improve and strengthen the findings of this study.

\section{RESEARCH FINDINGS}

The semi-structured interviews reveal several principles in reforming Agile-compliant performance appraisal as follows:

- Integrating individual and team performance assessment criteria

- Shifting to qualitative performance appraisal

- Aligning with Key Performance Indicators (KPIs)

- Assessing throughout a year

- Creating different appraisal forms

- Embracing customers' feedback

- Getting management support

- Conducting Transparent assessment (unfair assessment)

The principles are the guiding practices that support management and Agile teams in deriving and implementing an Agile-compliant performance appraisal. The detailed explanation for each principle in reforming Agile-compliant performance appraisal are discussed in the following subsections. 


\subsection{Integrating Individual and Team Performance Assessment Criteria}

In order to align with Agile practices, it is important to integrate team performance appraisal in relation to certain pre-established criteria and organizational objectives. Team performance appraisals assess the performance of teamwork including an individual's contribution to the team.

"It should be a combination of both; individual and team performance."-P1, Technical Project Leader.

The findings of this study indicated that the weight of individual and team performance appraisal varies and depends on the organization's goals and objectives. Balancing the measurement of individual and team performance, however, tends to help organizations to address individual skill development as well as focusing on achieving team goals.

"Certain criteria should be for an individual [assessment] and certain criteria should be on team aspect." - P1, Technical Project Leader.

Focusing on the individual assessment tends to cause negative competative amongst team members specifically for being a hero in a team. Many problems occurred when relying on the only single expert in a team such as demotivate others to perform in the team:

"When it comes to performance appraisal, if we do individual appraisals, persons who are low performers may get more demotivated. They don't have a spirit of the team. They don't see things as a team." - P2, Technical Project Leader.

The findings of this study indicated that many possible assessment criteria are used in performance appraisal of Agile teams. The choice of assessment criteria, however, should consider the integration between individual and team performance assessment specific for Agile teams. The selection of assessment criteria should reflect the significance of Agile team members' tasks and responsibilities within the framework of the team's and the organization's objectives.

\subsection{Shifting to Qualitative Performance Appraisal}

A common performance appraisal method is basically based on quantitative measurement, which is represented by using numbers or scores. A score enables a superior to indicate the level of their subordinates' achievement or performance, however, it is not adequate to provide feedback on how the subordinates can improve themselves. Thus, it is important to integrate a feedback section into performance appraisal for Agile teams. The score indicates the alignment of employees' performance with the defined Key Performance Indicators (KPIs), whereas the feedback works as an indicator as to what needs to be improved:

"I would prefer a verbal feedback because that would be more honest and more reflection on the current situation." - P1, Technical Project Leader.

A new direction for performance appraisal of Agile teams will require integration of qualitative feedback in performance assessment. Feedback can be obtained in a number of ways: observation and peerreview. Observation enables superiors to see and confirm the behaviour and performance of their subordinates before completing the performance appraisal. Superiors can also identify where and how the subordinates can improve themselves.

"Retrospective is used for team members to assess themselves and to improve as a team." - P1, Technical Project Leader.

Despite the benefits of qualitative feedback, there is no doubt that scoring systems can be used in performance appraisal of Agile teams. Scoring systems indicate the generic progress development of subordinates and also assist management in justifying salary increments for Agile team members.

"We have numbers used in our KPI chart. So we have to see which quadrant we are in. If we are in this quadrant, we have met expectation, we have met target that have been set to us, then we get a certain [salary] percentage of increment." - P1, Technical Project Leader. 
Therefore, integrating quantitative and qualitative measurement is essential for reforming Agile-compliance performance appraisal. Choosing and balancing the right measurement for the right assessment criteria of Agile-compliant performance appraisal.

\subsection{Aligning with Key Performance Indicators (KPIs)}

Reforming Agile compliance performance appraisal should align with KPIs that have been set by organizations. KPIs enable an organization to measure staff performance against key business objectives. Each Agile team member should know and aware the KPIs that need to be achieved for a certain period of time:

"We do the same with Key Performance Indicators (KPIs).Everybody know KPIs." - P3, Agile Consultant.

Choosing the right KPIs are vital to ensure the KPIs are attainable. It is important to avoid overwhelming KPIs that tend to neglect the exact value that the KPIs should achieve.

"The KPI s should not be too extensive. If it is so much KPIs, individuals are trying to achieve the KPIS and they might forget the values that need to be delivered." - P1, Technical Project Leader.

Reforming Agile compliance performance appraisal should not rely on the static KPIs.It is vital to periodically review the processes for monitoring and acting on the KPIs. Management should change KPIs that are no longer relevant and replace them with others that hold more value. This indirectly provide a space for identifying areas for improvement.

"A good measurement will stay alive for a while. But a good measurement is not fixed. It is progression. For example, if a team uses the same measurement for a while, then it is not recovering what we want and providing values, so change it." - P3, Agile Consultant.

It is norm for management to decide the KPIs that need to be achieved for every staff.Our findings, however, reveal that management gives freedom and space to every staff in deciding their goals which lead in setting the organization's KPIs:

"We have to write and set our goals. For example, I want to do unit testing. Then we have to specify the percentage that the goal should cover. Should it be $70 \%, 80 \%$ or $90 \%$ ? So at the end of the year or six months, we can evaluate whether we have achieved this goal or not." - P3, Agile Consultant.

The unique of Agile Software Development is appreciation and consideration towards staff or team members input in managing and assessing their work performance. Considering staff input will lead to choose the right KPIs, which indirectly assist in determining the right assessment criteria of Agile-compliant performance appraisal.

\subsection{Assessing Throughout a Year}

It is the norm for most organizations conduct performance appraisal at the end of the year. The annual performance appraisal, however, is not suitable to assess the performance of employees working in Agile software development projects:

"The traditional management has an annual review. That should not be the case because annual appraisal does not work." - P3, Agile Consultant.

Just like Agile methods, the performance appraisal should be done iteratively and incrementally. Our finding revealed that the performance evaluation should be done continuously throughout a year:

"A good measyurement is still alive for a while. But a good measurement is not fixed. It is progression." - P3, Agile Consultant.

The period or cycle of evaluation is vary depending on the preference and needs of assessment. It is advisable to have a shorter intervals of assessment instead of a long term assessment. Monitoring and reviewing the performance of each employee is more effective and efficient within a short period of time. 
"Review should be done everyday. So if i want to be truly Agile, review should be two weeks or four weeks." - P3, Agile Consultant.

Our findings indicated that some participants used milestones as a benchmark to assess the performance of Agile team members. Each iteration or sprint and release shall be considered as a milestone in Agile software development projects. For organizations involving many projects for every year, there shall be a possibility to review individual performance at the end of each project.

"It depends on how the assessment. It shall be through milestones or at the end of the project." - P1, Technical Project Leader.

Short interval and continuous assessment allows for identifying and acting on opportunities to improve performance appraisal. It tends to improve employees' engagement and provide a room for improvement.

\subsection{Creating Different Evaluation Forms}

Most organizations use similar performance appraisal form for all employees without considering their positions or roles. Participants, P1 and P2, however suggested to have different performance appraisal forms for different Agile roles:

"Should definitely have a different [appraisal] form." - P2, Technical Project Leader.

There are three main Agile roles namely team leader, team member, and product owner.

Each role should be assessed using different performance appraisal forms. Even though the team member consists of developers and testers, they should be assessed through the same assessment criteria. As Agile Software development emphasizes on cross-functional teams, team members need to understand each other's role and participate beyond their area of expertise. They do not just rely on their expertise in choosing tasks, but also tend to perform other tasks when needed.

"You cannot use the same [appraisal form] for developers.A developer is something else. Scrum master is something else [sic].”- P1, Technical Project Leader.

The performance appraisal form should be derived by emphasizing the core and job specific competencies for each role. The assessment criteria also should align with the specified goals for each role.

\subsection{Embracing Customers Feedback}

Customers involvement in Agile teams is vital in providing feedback on the improvement of software product development. Agile teams have to be opened to accept feedback, and start to divide the feedback into several user stories for better prioritization. The customer feedback, however, should be taken into account for performance appraisal. Our participant, P2, indicated that customer feedback for each project should be considered in performance appraisal:

"We have a survey that we send to our customers. We did after the project is done." - P2, Technical Project Leader.

The customers are the source of the project and indicators to the successful of software project development. It is prevalent to fulfill their needs which indirectly tends to influence the performance of each team member in the project.

"It is possible if the product owner give rate to everyone in the team. If he is very happy, and he knows that his business is being satisfied with the business needs, that means the team is doing a good job [sic]." - P1, Technical Project Leader.

Therefore, management should consider the customers' feedback in assessing the performance of employee in Agile teams. The assessment criteria of customers' feedback should be included in the Agile-compliance performance appraisal. 


\subsection{Getting Management Support}

A transition to Agile methods will not succeed without management support.Management roles is prevalent in supporting the execution of Agile methods, as well as reforming the Agile-compliant performance appraisal. Moving from waterfall model to Agile methods is not just focused on faster deployment of the software, but it should reflect to overall transition of Agile methods including performance appraisal.

"But I see a lot of organisations doing that and they use Scrum or Extreme Programming (XP) as an excuse to do things faster." - P3, Agile Consultant.

According to participant P3, his organization that he is working on has cascaded the organization hierarchy by emphasizing on employee instead of management and board level. Oppose to traditional approach, employee is set up at the top level of organization hierarchy. Employee voice exists where everyone is able to project their opinion and express their feeling, and their views taken into account when decisions are being discussed that affect them:

"If you go to Agile organisations, you can see that the triangle is reversed. Employees on top, then management, then board level. Problems go top down, and solutions go bottom up." - P3, Agile Consultant.

Managers or team leaders should play an important role in performance appraisal processes by explaining to employees to attain organization's goals and understand their job duties and expectations. They have to take part by facilitating and encouraging employees in achieving the desired goals and KPIs.

“Managers are responsible for everybody individual performance.” - P3, Agile Consultant.

Therefore, reforming Agile-compliant performance appraisal requires a strong interconnection between management and employess. Without support from management, it is impossible to produce and implement a good and effective Agile-compliant performance appraisal.

\subsection{Conducting Transparent Assessment}

Transparency is the extent to which all employees know and understand what is required in the performance appraisal and also know how they will be assessed fairly. They need to aware and know how they can react to achieve the desired goals and KPI. The appraisal form should be visible to everyone in order to be a guideline for performing well in accomplishing their work and responsibilities. Transparency is existed and implemented in Agile practices such as daily stand-up meetings, retrospectives, and sprint reviews. These practices facilitate the peer reviews and open to all for assessing other team members and themselves as well:

"Peer review should be open. So what we want in a daily stand-up is that people are really open to each other. Constructive but open. So if they feel that one of their peers in the team is not performing, they do not hide and voice out behind their back. That should be done face to face in a constructive way.So the whole team can learn from that." - P3, Agile Consultant.

Visual management is an absolutely essential tool to display information about the desired goals, expectation and achievements. Visual management is a communication tool that links between data and people. This tool should enable the Agile team members to see the current state of work and track how he or she and team are performing versus goals:

"I find visual management is really important. So everybody can see. Tranparency is a key. So on the wall, everybody can see how they perform." - P3, Agile Consultant.

The concept of equity or fairness is extended from the transparency. A lack of transparency tends to cause frustration due to bias and unfair judgement and assessment. As mentioned by participant P1, the unfair assessment was happened in his working environment due to poor and weak assessment methods:

"The management is not fair in assessing the current skill set. The management wants that individual to pick up a new skill set, but they do not follow the progress of that individual. So, the individual 
might already has that required skill, but he does not know how to show or how to prove it." - P1, Technical Project Leader.

Ensuring fairness by avoiding bias can be a complex and difficult affair. Therefore, transparency should not be neglected in reforming Agile-compliant performance appraisal. Choosing the right technique or method is vital to ensure transparency assessment exists in Agile-compliant performance appraisal.

\section{DISCUSSION}

The initial step in constructing performance appraisal is the determination of performance criteria. Besides individual assessment criteria, our findings indicated that team performance criteria should be included in Agile performance appraisals, to reflect the team-level performance. Team collaboration is not easy to implement if performance appraisal mechanisms are based on individual performance. This is aligned with Alnaji and Salameh's study [7], which posits the importance of individual and team performance assessment criteria in performance appraisal, in order to fit into an Agile Software Development environment. Our findings support Noori et al.'s study [5] which indicates the need for selecting and updating performance criteria. The performance criteria should be aligned with Agile values, principles, and practices, as well as an organization's goals and objectives. Furthermore, balancing the right weight for individual and team performance assessment criteria is vital to reflect the true abilities of individual and Agile teams as well. Developing team-based performance criteria, however, should reflect Agile core values, principles and practices. Another aspect found with ineffectiveness of traditional appraisal system is the feedback information is kept outside of the assessment tool. It is important that the performance appraisal capture continuous feedback to enable employees develop themselves for allowing them to keep align with organization expectations. From interviews and survey results, most participants prefer to receive continuous feedback from managers and peers as well. Tripp and Riemenschneider [8] also indicate the importance of qualitative feedback in providing the employee with clear information about his or her performance. Qualitative feedback enables Agile team members to identify areas of strength and weakness, analyse their performance gaps, and take action for improvement.

Our findings are aligned with Ahmad and Bujang's study [13], which posits that qualitative feedback does not replace the scoring appraisal, but it can be used as an additional method of appraisal. Through our observations, feedback can also be gained during retrospective meetings. These meetings allow Agile teams to reflect on the work process used and how to improve the process for the next iteration. The outcome of retrospective meetings is feedback, which tends to influence the performance appraisal. Our findings, however, contradicted Shankarmani et al.'s study [14], which claims that Agile teams do not need performance appraisal other than retrospective meetings. Based on our observations, relying only on the retrospective meetings is not adequate for gaining feedback and ensuring the reliability of performance assessment. Qualitative feedback throughout peer-to-peer feedbacks tend to promote knowledge sharing. This scenario could be happened when team members contribute their expertise for helping each other $[15,16]$. This indirectly supports expertise coordination, when sharing expertise requires team members to rely on each other for locating, recognizing, and accessing expertise [17-19]. Deriving KPIs should focus on team goals not on individuals due to nature of Agile methods [7, 20]. The process starts with defining organizational goals and then setting employee goals. This process has more sense when organizations define business goals and link them to the performance metrics that need to be monitored. These metrics then become the KPIs for the development team and individual. Interview results highlight the need for having continuous performance appraisal system. Just like Agile software development, the performance evaluation shall not be annual and it should be done iteratively and incrementally. Our findings in-line with Saeed and Sundararaman [20] in terms of assessment period, which there shall be a possibility to review individual performance at shorter intervals rather than annually.

Our findings revealed the need for different evaluation forms derived for different Agile roles. This is contradicted to ordinary performance evaluation which normally using similar evaluation for different working positions. Hall [21] in his slide presentation entitled "Performance Appraisal for Agile teams", however presented different attributes of assessment for Scrum masters and product owners. This clearly indicated the needs for different attributes assessment for different Agile roles in order to create more effective and fair performance assessment. Our findings strongly support the role of management in reforming Agile-compliant performance appraisal. Similar to Saeed and Sundararaman's study [20], they have discussed Management by Objectives (MBO) principles in evaluating employee performance in Agile work environment. Even though management is responsible to manage performance appraisal, management should not neglect input from employee. For instance, MBO principles do not allow management to determine the objectives by themselves, but the objectives should be defined by employees and management. 
These defined objectives and KPIs lead to embark on transparency in the whole process of appraisal performance.This is contradicted to traditional performance appraisal where the traditional approach is not emphasized on transparent, open and collaborative assessment [20, 22]. Since it is closed approach, team members will be unaware of other's goals and KPIs, and consequently hard to work together cohesively as a team. Therefore, our findings have shown the need to set up transparent assessment criteria and approaches in performance appraisal for minimizing unfair and bias judgement. This is aligned with Prasad's study [23], which suggested that organizations are convinced to invest ample time and innovation in designing and appraising staff transparency, in order to minimize the element of conflict and prejudice. Specific in Agile software development, various artefacts are used to enable transparency of works progress and team's productivity. The findings of our study do not indicated any artefact that support transparency in appraisal performance.Use of a Kanban board and burndown chart, however, allows each team members to be monitored in terms of progress and reflect the performance for each member $[24,25]$.

\section{CONCLUSION}

This paper presents principles of reforming an Agile-compliant performance appraisal for Agile teams. The principles are the guiding practices that support management and Agile teams in deriving and implementing an Agile-compliant performance appraisal. These principles tend to support management in determining assessment criteria and methods used for assessing the performance of Agile team members. Effective performance appraisal aligning Agile values, principles and practices enables managers in organization to evaluate software team members in fairly and consistent manner. Motivation amongst members may increase, and this is able to produce capable workforce to perform at higher level.

\section{REFERENCES}

[1] R. Barrett., "Labouring Under an Illusion? The Labour Process of Software Development in the Australian Information Industry," New Technology, Work and Employment, 16(1), 18-34, 2001.

[2] K.V.L. Manasa, et al., "Role of Training in Improving Performance," The IuP journal of soft skills, 3(3), 72-80, 2009.

[3] J.N. Cleveland, et al., "Multiple Uses of Performance Appraisal: Prevalence and Correlates," Journal of applied psychology, 74(1), 130, 1989.

[4] M.Z. Iqbal, et al., "Effectiveness of Performance Appraisal: An Integrated Framework." International Journal of Management Reviews, 17(4), 510-533, 2015.

[5] S. Noori, et al., "Human Performance Factors in the Evaluation of Virtual Organizations," International Journal of Business and Management, 4 (2), 41, 2009.

[6] S. Coyle, et al., "People Over Process: Key People Challenges in Agile Development," IEEE, 2010.

[7] L. Alnaji, et al., "Performance-Measurement Framework to Evaluate Software Engineers for Agile SoftwareDevelopment Methodology, " European Journal of Business and Management 7(2), 183-190, 2015.

[8] J.F. Tripp, et al. "Toward an Understanding of Job Satisfaction on Agile Teams: Agile Development as Work Redesign. In System Sciences (HICSS), 2014 47th Hawaii International Conference, IEEE, 3993-4002, 2014.

[9] M. Rejab, et al. "Transition to Agile method without Agile-compliant performance appraisal?." In AIP Conference Proceedings (Vol. 2016, No. 1, p. 020088). AIP Publishing, 2018.

[10] M. Rejab, et al. "Reforming performance appraisal for Agile software development projects ", International Journal of Engineering and Technology, 7 (4.19), 233-239, 2018.

[11] L. Dubé., "Teams in Packaged Software Development: The Software Corp. Experience,"Information Technology \& People, 11(1), 36-61, 1998.

[12] S.L. Jarvenpaa, et al., "Operational Capabilities Development in Mediated Offshore Software Services Models", Journal of Information Technology, 23(1), 3-17, 2008.

[13] R. Ahmad, et al., "Issues and Challenges in the practice Of Performance Appraisal Activities in the 21st Century," International Journal of Education and Research, 1, 4, 2013.

[14] R.Shahkarmani, et al., "Perforrmance Assessment of ASD Team Using FPL Football Rules as Reference," In India Conference, 2011, 1-4, Annual IEEE, 2011.

[15] Kutay, et al., "Knowledge transformation for education in software engineering," International Journal of Mobile Learning and Organisation 1, 12006 , pp. 58-80.

[16] G. Lohan, et al., "Beyond budgeting and agile software development: a conceptual framework for the performance management of agile software development teams," 2010, pp. 162.

[17] M.Rejab, et al., "Distributing expertise in agile software development projects," In Agile Conference (AGILE), 2014, IEEE, pp. 33-36.

[18] M.Rejab, et al. "Locating expertise in agile software development projects," In Agile Processes in Software Engineering and Extreme Programming. Springer, 2014, pp. 260-268.

[19] M. Rejab, et al., "Coordinating expertise outside agile teams," In International Conference on Agile Software Development, Springer, Cham, 2015, pp. 141-153.

[20] F. Saeed, et al. "Employee Performance Evaluation in Agile Work Environment", 2018.

Indonesian J Elec Eng \& Comp Sci, Vol. 16, No. 2, November 2019 : 1009 - 1017 
[21] M. Hall, "Performance Appraisal for Agile Teams.," https://www.stickyminds.com/sites/default/files/presentation/file/2013/12CADPW_AT8.pdf, 2003. [Online; accessed 11- December-2018].

[22] M.A. Rizvi, "A Feedback Model for an Effective Performance Appraisal System," Journal for Global Business Advancement, 10(2), 140-157, 2017.

[23] P. Prasad, "Performance Appraisal: An Empirical Study To Understand Job Satisfaction And Motivation Of Personnel Through The System." International journal of engineering and applied sciences, 2(4), 3-20, 2015.

[24] D. Owens, et al., "Project Management Assurance in Agile Projects: Research in Progress," 2018.

[25] H. Sharp, et al. "The Role of Physical Artefacts in Agile Software Development: Two Complementary Perspectives," Interacting with Computers, 21(1-2), 108-116, 2009. 